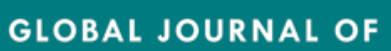 \\ Community Psychology Practice
}

\section{PROMOTING COMMUNITY PRACTICE FOR SOCIAL BENEFIT}

\section{Community Psychology at a Regional University: On Engaging Undergraduate Students in Applied Research}

\author{
Amie R. McKibban and Crystal N. Steltenpohl ${ }^{1}$
}

Author Biographies: Amie R. McKibban, is an associate professor and department chair of psychology. Much of her work at the University of Southern Indiana has focused on sexuality, with an emphasis on sexual and gender identities in the local community. She is currently involved in research on sexual and gender identities, sexual and gender minority policy in public education, and attitudes toward aging. Crystal N. Steltenpohl, is an assistant professor of psychology and founder of the Online Technologies Lab at the University of Southern Indiana. As a scholar, gamer, and participant in online worlds, her major research interests revolve around how we interact with various technologies, especially those that house online communities. She is particularly interested in understanding how technologies influence communities, the self, and health behaviors.

Recommended Citation: McKibban, A. R., Steltenpohl, C. N. (2019). Community Psychology at a Regional University: On Engaging Undergraduate Students in Applied Research. Global Journal of Community Psychology Practice, 10(2), 1-14. Retrieved Day/Month/Year, from (http://gicpp.org/).

Author Note: Correspondence should be addressed to Dr. Amie R. McKibban, College of Liberal Arts 3042, 8600 University Boulevard, University of Southern Indiana, Evansville, IN, 47712, armckibban@usi.edu.

${ }^{1}$ University of Southern Indiana 


\title{
Community Psychology at a Regional University: On Engaging Undergraduate Students in Applied Research
}

\begin{abstract}
Engaging students in service learning projects grounded in community psychology values and practices when working in a rural, conservative area provides several challenges and opportunities for faculty members. The authors share processes and outcomes from three case examples taking place between 2010 and 2013: (1) running focus groups and survey development with a local YMCA branch that predominantly serves people of color in low income housing, (2) the development of a strategic plan for the implementation of an art crawl in the local downtown community, and (3) the development and execution of an asset map evaluating supportive resources and spaces available to the local LGBTQA community. The authors reflect on feedback from students and community partners. These case examples highlight the complexity of balancing students' skillsets, work and other life obligations, and desire to use classroom knowledge in community settings. It also highlights the importance of preparing community partners for working on applied research. We provide recommendations based on each project's challenges and successes for universities and communities of similar demographics. Working in rural, conservative settings provide their own challenges and opportunities, but are well worth it if implemented in an intentional way, and more research is needed to strengthen our understanding of how best to engage students from a variety of social and political backgrounds.

The Society for Community Research and Action (SCRA) lists four broad principles and various concepts that guide community psychologists (Society for Community Research and Action, n.d.b). These principles and guiding concepts highlight the importance of valuing diversity among people and settings, understanding context, engaging in collaborative ventures that respect community needs and preferences, promoting social justice values, and utilizing change strategies at multiple levels. Further, SCRA outlines various competencies for practice in our field, which focus on foundational principles, community program development and management, community and social change, and community research (Society for Community Research and Action, n.d.a). These competencies offer a framework for understanding how community psychologists achieve the goals outlined in the principles and guiding concepts and an

opportunity for educators to reflect upon their pedagogical practices.

Community psychologists in academic settings can use service learning projects as one means of introducing students to SCRA's principles, guiding concepts, and competencies. While there is a general agreement that service learning is a form of experiential education, there remains disagreement on what, exactly, service learning looks like. According to Howard (2003), service learning generally entails three key components: (1) service is provided to the community, (2) students' academic learning is strengthened, and (3) students' commitment to social responsibility is strengthened. One avenue to provide service learning opportunities to students studying community psychology is to engage in applied research projects, partnering with community organizations and networks. Depending on community contexts, however,
\end{abstract}


it can be difficult to create opportunities for students to engage in applied experiences in line with SCRA's principles, guiding concepts, and competencies. As a field, we struggle to find the most effective ways for engaging students in and teaching them the skills they need for community practice (Francescato \& Zani, 2013). It is important for instructors to be reflective about their teaching practices and understand community and university contexts when designing classroom experiences for students studying community psychology.

In this paper, we highlight successes and challenges of working with undergraduate students at a regional university in southern Indiana. To do so, we illustrate three case examples: (1) focus group and survey development with a local YMCA branch predominantly serving people of color in low income housing, (2) the development of a strategic plan for the implementation of an art crawl in the local downtown community, and (3) the development and execution of an asset map evaluating supportive resources and spaces available to the local LGBTQA community. Each case example is more involved and complex than the last regarding the skillsets taught and outcomes evaluated. We will provide recommendations based on these challenges and successes for institutions and communities of similar demographics.

We hope this will provide insight into the practice of community psychology with undergraduate students residing in more rural and conservative areas, given many US universities are situated in such areas. Further, we will illustrate that the teaching of community psychology, and more importantly engaging students in applied research, often serves as the first time students are exposed to a community-level perspective of human behavior. We hope this illustrates areas where we can further develop strategies to engage students from a variety of political and social backgrounds.

\section{Community Context}

Demographics. The University of Southern Indiana is located on the outskirts of Evansville, in Vanderburgh County, which serves as the regional hub for a tri-state region (Illinois, Kentucky, and Indiana). The tri-state region itself is heavily rural, with a population of 474,251 . Vanderburgh County itself (population of 181,877 ) is homogenous, with $86 \%$ of the population classified as white and non-Hispanic (9\% Black, 6\% other). The county tends toward a relatively high poverty rate of $17.4 \%$ (above the national rate of $12.7 \%$ ), which may also be reflected in the county's educational attainment, with only $24.9 \%$ of the population holding a bachelor's degree or higher (significantly below the national rate of 33\%; US Census, 2016). A slight majority $(53 \%)$ adheres to religious institutions, with the largest representation (22\%) identifying as Evangelical Protestant (US Religion Census, 2010). Demographics of the surrounding area mirror those of Vanderburgh County.

As is common with many regional universities, the majority of USI students are from Indiana (83.2\% in state, $14.6 \%$ out of state, $2.2 \%$ international), with $44 \%$ of those students coming from Vanderburgh and contiguous counties and $27.2 \%$ from other Indiana counties (USI Fact Book, 2017). Of the 9,014 undergraduate students enrolled, $80.5 \%$ are attending full time with $76.6 \%$ classified as traditional (24 years old and younger). As such, almost a quarter of our students are non-traditional. Racial demographics closely mirror that of the region, with $85.8 \%$ classified as white, $11.9 \%$ as non-white minority, and $2.2 \%$ as international. Faculty demographics are similar (88\% white, 9\% non-white minority, $2 \%$ international).

Institutional Positionality. Undergraduate student engagement in applied projects is not only supported by the university but encouraged through our classification as a 
Community Engaged University through the Carnegie Foundation for the Advancement of Teaching, making our community psychology course a seamless fit with the mission and vision of the university itself. At the University of Southern Indiana, the course is offered as an upper level undergraduate elective for majors and minors within the department. However, many other students can enroll in the course, as introduction to psychology and social psychology are the only prerequisites to the course. Frequently, these students come from service and healthcareoriented majors, taking the course to fulfill an upper level general elective. Therefore, community psychology is taught to a diverse group of students, particularly regarding their interests and educational background. This combined with the percentage of students holding jobs (75\% working 10 or more hours a week, $45 \%$ working 20 hours or more a week) and living off campus (88\%) can create unique challenges in the way we engage students and ultimately the projects we choose. The relationships the students have with their community is best understood in the context of a region that is rural and conservative, both politically and economically. This has also provided unique challenges, and unexpected successes in teaching community psychology research to undergraduate students.

Author Positionality. The first author completed her PhD in community psychology at Wichita State University in 2009. Following the completion of her degree, she began a tenure track position at the University of Southern Indiana, where she developed an undergraduate course in community psychology as part of the departmental curriculum, and which serves as the basis for this publication. She has worked in the southern Indiana community in outreach and program development for the last nine years while earning tenure and promotion, including the development of an LGBTQA asset mapping project called Map Evansville. She currently sits as department chair of psychology at the University of Southern Indiana.

The second author was a student with plans to be a social psychologist when she took community psychology--then a special topics and not a standing course--from the first author. Her experiences in the course and working on the YMCA project altered her career trajectory, and she earned her $\mathrm{PhD}$ in community psychology at DePaul University. During her time at DePaul, she continued to work with the first author on Map Evansville. She has returned to USI as a tenure-track faculty member in the psychology department, currently overseeing the internship course for psychology undergraduate students and the community psychology course on a regular rotation as of Fall 2018.

\section{Case Studies}

\section{YMCA Caldwell Center}

Project description. In Fall 2010, 23 students teamed up with the YMCA Caldwell Center located in Glenwood Neighborhood, a racially diverse, economically disadvantaged area with $46.8 \%$ of the residents living below poverty and $53.5 \%$ having less than a high school education. This location was chosen given its demographics and ease of alignment with the SCRA guiding principles and concepts, namely diversity among people and settings, contextual understanding, and engaging in collaborative efforts that incorporate community needs and preferences. The goal of working with this YMCA branch was twofold: the project aided students in developing real-world, marketable skills relevant to community psychology research, and the community partners had assistance in developing a tangible product that could be utilized to better serve community member needs. This partnership was established through the university's Outreach and Engagement office, which is designed to connect community entities in need of services with researchers and professors on campus, and relevant to 
this project, to develop service learning projects with tangible outcomes. Institutional Review Board approval was granted through normal university procedures prior to the start of the project.

The collaborative effort rested on two demonstrable outcomes for the Caldwell Center: to provide qualitative feedback from different age groups utilizing their services (a bottom-up focus on resident needs) and create a quantitative measurement tool that could be used to collect data more easily and quickly once we ended our partnership. Given the vast difference between our students (largely white, middle class, and educated) and the residents utilizing the center, it was imperative to design the project in a way that allowed the students to become acquainted with the center and develop a sense of investment and rapport before the creation of deliverables. As such, during the first two weeks of class, each student visited the Caldwell Center to observe activities (health and wellness programs, games, etc.) for a minimum of 30 minutes. Following their observation, they wrote a field report allowing them to connect their observations back to classroom material and to reflect upon their own perceptions and potential biases. This not only allowed for the students to build rapport with the Caldwell Center, but for discussion of potential biases and assumptions when working with a racially diverse community. These conversations took place on two separate occasions in the classroom, both with and without, representatives from the Caldwell Center present.

Students were then divided into research teams and trained to conduct focus groups with community members. Training was conducted in the classroom by another researcher who specializes in focus groups. This training included lecture and hands-on simulations, affording the students the opportunity to demonstrate competency. Once properly trained, the teams visited the center and ran focus groups with the following age groups (one focus group per age group): 3 rd-5th grade (9 participants), middle school (15 participants), high school (8 participants), and adult (7 participants). Teams submitted their findings from each session in written form. Two representatives from the YMCA then visited the class to discuss what was found and elaborate on any findings that may have been ambiguous, as a form of member checking.

Utilizing information garnered from focus groups and meetings with YMCA representatives, teams then spent the remainder of the semester developing a survey instrument to assess the needs and wants of the community members the Caldwell Center serves in each respective age group. Throughout this process, literature from community psychology (e.g., cycling of resources, ecological systems, etc.) was presented through lecture and processed in small group work to ensure the material from the classroom remained connected to the service learning project. The questions developed by each team were edited and formatted by the first author, resulting in three usable survey instruments. Each team presented their results and lessons learned at the end of the semester. Several of the Caldwell Center's staff and community members attended the presentations, further ensuring rapport and establishing closure.

Student experiences. Students were asked about their experiences in this course at midterm, utilizing a formative evaluation and an outside evaluator, and at the end of the semester utilizing the university's summative teaching evaluation instrument. At midterm, students largely expressed satisfaction with the course, with two notable themes for improvement: they unanimously disliked the textbook, and some found it cumbersome to have to leave campus to participate in the class project, suggesting a project in the future where a bulk of the work was done on campus and in class. 
By the end of the semester, concerns regarding the text remained, while concerns about off campus project work were not as pronounced. For example, one student indicated, "This has been one of my most rewarding classes in college so far. I really think actually leaving the classroom and going out into the community to do a project helps us to get the real-world applications of what we learn in class." It is important to note students with initial reservations about working off campus may not have provided qualitative feedback at the end of the semester.

Quantitative results from the university's summative course evaluation were positive (4.81 on a five-point scale) compared to normative comparisons across campus (4.23). Students felt they learned a lot in the course (4.81), performed up to their potential (4.44), and that the assignments helped them increase their understanding of the course content (4.81). As alluded to above, qualitative feedback corroborated the quantitative feedback. To illustrate, some of the comments from students included,

- "Very interesting look at a subject I had never really considered before."

- "I feel I have learned more from this single course than from the three other psych classes I am taking combined."

- "The service learning project has given me experience which I will be able to utilize in the working sector."

- "This course turned out to be much more rewarding than I initially anticipated."

- "Although there was much information to cover in this class, Dr. McKibban presented it to the class in a way that we could apply it and understand it in our project, which helped us to retain it with much greater ease."

Organization experiences. The YMCA Caldwell Branch's experiences with the project can be considered from two perspectives: that of the focus group members and that of the representatives and staff. Although we did not systematically evaluate participant satisfaction, feedback from the representatives indicated the youth (all age groups) and adults appreciated the opportunity to voice their opinions about programming, and most notably in the high school and adult groups, the opportunity to voice concerns about the center itself, particularly regarding staffing and safety. Throughout the project, the representatives were impressed with the level of professionalism exhibited by students and their willingness to listen and adjust their language so that the local youth could more easily interact with them. They were also surprised by the quality of information gathered. During a follow-up conversation eight months after the conclusion of the project, the representatives indicated they were continually using the data gathered to modify programming. They further indicated the utilization of the surveys had allowed them to gather data and successfully apply for grant monies.

\section{Art Crawl}

Project description. For the following year, two considerations informed the development of the project. First, based on feedback from the previous year, students were given primary sources in place of a textbook. These sources included journal articles and Community Toolbox materials. Given there were numerous students at midterm the previous year indicating a preference to do more work on campus and a project that focused on community development more broadly, we did not work with a designated community partner, but focused on multi-system, program development and a more multifaceted, marketable skillset. This project was developed with the SCRA competencies of community program development and management, community change, and research in mind. As such, 20 students produced a strategic plan for a monthly art crawl (a three-to-four hour event once a month during which community members 
visit local businesses displaying artists' work, often involving live music, drinks, and food) for downtown Evansville in the fall semester of 2011. The first author reached out to local artist groups, business owners, and community members to arrange the partnerships. Institutional Review Board approval was not sought in this project given no unique data was being collected or utilized for dissemination. This decision was supported and approved by the IRB.

Students were trained in survey question development, interview techniques, and data collection with existing data banks throughout the semester by the first author and another professor on campus who specializes in interview techniques and focus groups. This latter training was like what took place in the first case study where students learned through lecture and handson simulation. To develop the sections required of a strategic plan, students conducted interviews with artists, potential artists, business owners, and community members (each student interviewed two community members) and used data from city sources and the U.S. Census. Students produced vision and mission statements for the project that gave voice to the community and embraced differing ideas within that community. In the same manner, students conducted a SWOT (Strengths, Weaknesses, Opportunities, and Threats) analysis regarding the area's strengths and weaknesses (associated with downtown), and opportunities and threats (associated with Evansville and the broader Tri-state area). Students also collected demographic data on the community, downtown business area, and local artistic groups. The analysis took into consideration the needs of the artists, potential artists, business owners, and community members regarding the functionality and sustainability of an art crawl.

Students then composed a project statement and rationale for the art crawl. This statement and rationale included objectives of the plan, fiscal benefits of the crawl, benefits regarding human welfare, and the benefits of fostering a sense of community. Students also completed an action plan, including measurable goals, objectives, and activities. The action plan mapped out the art crawl in its entirety and was thorough enough to function as a blueprint for implementation. To iterate the importance of evaluation, students developed an evaluation plan, which included suggestions on formative evaluation measures (how are things going from monthmonth) and outcome evaluation measures (is the art crawl successful overall). The evaluation plan offered a way to tangibly measure the goals and objectives with their respective outcomes in the action plan. It is noteworthy students worked in teams when gathering information throughout the semester, but ultimately wrote individual action and evaluation plans.

Student experiences. Although students reported the class was beneficial, throughout the semester they struggled to make the connections between the art crawl and community psychology. Despite every effort to make this connection, in the end, students found this project less beneficial compared to the previous year. This observation is based on informal feedback gathered mid-semester and at the end of the semester. Although students' feedback on formative evaluations mid-semester suggested utilizing primary sources was beneficial and preferable, this class performed significantly lower on examinations than previous semesters. This suggests they may not have understood the material to the level expected. This may also reflect the difficulty many students have with comprehending primary sources over secondary sources, such as textbooks. This decreased understanding of the material may have ultimately resulted in less satisfaction with the course overall, indicated by end of the semester summative evaluations (4.57, compared to 4.81 the previous year). Further, students rated the class lower on whether they felt they learned a lot in the course (4.33, compared to 4.81), performed up to their 
potential (4.0, compared to 4.44), and most notably that the assignments helped them increase their understanding of the course content (3.89, compared to 4.81). Qualitatively, some students found the course, and project, helpful as illustrated by one student in the following comment:

"This course was very informative and very useful. The hands-on approach that Professor McKibban used was effective in not only teaching the material, but also showing the practical application. This connection from theoretical to practical is sometimes difficult for students to make. This course has provided me with experience and a skillset (strategic planning) that will be useful throughout my life."

While most found the material to be taught well, they struggled with their involvement in the project as can be seen in their feedback below.

- "I liked this class because it was hands on. Aimee [sic] is my favorite teacher and she makes the subject easy to relate with. I felt the material was repeatitive [sic]. I wish we could have been more involved in the project."

- "Although some of the material is pretty dry, Dr McKibban makes it enjoyable! I cant [sic] wait to see the finished product next semester. I think the only issue for this course is most of the students will not get to be a part of the finished product but have done a lot of the leg work. Being involved with the art crawl until it starts would perhaps make students more invested in the project."

- "This was an interesting class for me. I learned a lot, but I wish we could have had more say into what project we did for the semester."

Organization experiences. Although this project was not completed in partnership with a specific community partner, a few comments regarding organizational experience, understood in the context of community experience, are warranted. At the time of this project, discontent existed within the local art community, particularly between two local groups. One of these groups expressed an appreciation for the possibility of "getting the conversation started" between the different fractions in the community. Further, the downtown business community, although poised for an uptick in development, was just beginning to have meaningful conversations with the city redevelopment commission. Although business owners were happy to be interviewed and genuinely interested in assisting the students with the project, they expressed no real interest or investment in the idea. At the conclusion of the project, the best parts of each action and evaluation plan were combined and given to the then director of the local arts council. Unfortunately, this director left the area the next year. Although an art crawl downtown was never implemented, one local business began to hang local art in his establishment. Further, a monthly art crawl eventually took root in a neighboring district, although its connection to any action of this project is unknown.

\section{Map Evansville}

Project description. In the fall semester of 2013, 25 students (21 enrolled in the class and four student research assistants) worked with members in various LGBTQA communities to develop an assessment tool that would eventually be utilized in the development of a LGBTQA-focused asset map of Evansville and the surrounding areas. This project was designed to be the initial planning phase of a larger, grant-funded, project that would be launched live (website to collect data from service providers for the asset map) by the end of the following summer with the help of the second author (Map Evansville, n.d). Pre-existing partnerships the first author had established over the years working in the LGBTQA community were utilized and proper IRB 
approval was obtained. With the differences between the two previous projects in mind, this project was developed to give students more contact with community partners, more hands-on experience outside of class, an opportunity to learn about the importance of contextual and historical understanding of a community, and the ability to engage in a collaborative effort incorporating community needs and preferences, in line with SCRA competencies.

Like our first case study, guest speakers from two groups serving the local LGBTQA community visited class for in-class discussions with students. This discussion was moderated utilizing an interview schedule for each speaker, developed by the students and modified by the first author. This interview phase was important in beginning the initial phase of defining what "inclusivity" meant for the local LGBTQA community. Students were then assigned to one of five research teams, with a research assistant assigned to each team, and the first author assigned to the fifth team. Students were trained to conduct focus groups, including cultural awareness when working with the LGBTQA community (for example, the use of appropriate vocabulary). Focus group training was conducted by the same professor as in the first two case studies (including simulations), and cultural training was conducted by the first author, which included working through scenarios to ensure competency prior to entering the community. Utilizing information collected from community partners, each team developed an appropriate focus group protocol, dependent upon their assigned sector of the LGBTQA community. Once properly reviewed and practiced in the classroom setting, the students ran focus groups with a LGBTQA youth group, a local trans group, the university's LGBTQA student group, a group of LGBTQA faculty and staff, and a local LGBTQA early adulthood group. Once the focus groups were completed, teams submitted their findings in written form.
Utilizing data from the focus groups, interviews with organizational representatives, and evidence-based practices from the Human Rights Campaign Equality Index and the National Assessment Tool Questions for Pride Indexes, the teams spent the remainder of the semester developing an instrument to assess the inclusivity of service providers in the area, regarding services provided and employment practices. At the end of the semester, each group presented on what was done, lessons learned, insights students had regarding community psychology, and students' understanding of community psychology as an applied field. Community members were invited to watch and ask questions, which was important to ensure the assessment was a good fit within the city's historical and cultural context, a critical aspect to asset mapping.

Student experiences. Students were asked about their experiences during a formative evaluation mid-semester and at the end of the semester in a summative evaluation. The themes that emerged (formative and summative) in the qualitative feedback were in line with previous years. For example, students appreciated the hands-on experience with focus groups. More specifically, students felt they not only learned about community psychology, but about themselves. As illustrated in one student's comment, "I really enjoyed the real life aspect of the course and the focus groups that were done outside of class time. I feel like I not only learned a lot about Community Psychology, but also about myself." Indeed, many students expressed these sentiments during the formative evaluation and in personal communications. Given this project focused on the LGBTQA community at a time when the national conversation was active (e.g., marriage equality), students appeared to be more personally invested in ways that allowed them to re-examine their own assumptions and biases. Overall quantitative feedback increased once again to levels similar to the first case study as compared to 
the second (4.73 overall class satisfaction, up from 4.57), and particularly compared to normative comparisons across campus (4.31). Students felt they learned a lot in the course (4.89, up from 4.33), performed up to their potential (4.50, up from 4.44), and that the assignments helped them increase their understanding of the course content (4.63, up from 3.89).

Organization experiences. The organizational experiences with the project can be considered from two perspectives, like the first case study: that of the focus group participants and that of the organizational representatives. Feedback from focus group participants notably indicated a sense of relief that someone was finally listening to their needs regarding the local community and that the product of the entire project (an interactive, online resource guide) would be developed in a way that allowed them to define what inclusivity meant (as opposed to people outside of the community making those decisions). Throughout the project, both representatives were impressed with the professionalism exhibited by students and their willingness to listen and learn. They were impressed by the quality of information gathered, particularly from our transgender community members. Once the class ended, both authors continued to have contact with one of the representatives over the course of approximately nine months in preparation for the launching of the assessment and ultimately the asset map.

\section{Challenges}

There are several challenges to consider when including service learning projects in community psychology courses at institutions comparable to USI. First and foremost, students need to be well-prepared to enter community settings, which requires an understanding of community psychology concepts and the community with which they will be working. While students appeared satisfied with the opportunity to gain handson experience in the community, they expressed dissatisfaction both with community psychology textbooks and primary materials. Further challenges emerged when considering their preparedness to enter a community setting with which they were unfamiliar. To illustrate, $98 \%$ of the students participating in the strategic planning of an art crawl in the downtown neighborhood had never visited the area during their three to four years at USI. Likewise, the majority of students did not have experience with either low-income Black or LGBTQA communities. Although students appeared eager to learn more and subsequently adjust their world views when working with the LGBTQA community, such a shift in perspective did not appear to happen with the other communities. For example, in the final reflections from the YMCA project, students focused more on individual factors contributing to poverty and other obstacles participants mentioned (e.g., poor grades could be improved with better discipline), as opposed to structural factors. The first author took this opportunity to revisit structural oppression and have open dialogue to address these challenges during class.

Some of this may also be due, in part, to different conceptualizations of course-related concepts. Some research suggests there are three conceptualizations of what makes someone a "good citizen": someone who is personally responsible (a more conservative view), someone who participates in society, and someone who is justice oriented (a more liberal view) (Westheimer \& Kahne, 2004). It is likely easy to think of different ways students may interpret other concepts in community psychology. Given the often personal and political nature of many topics in community psychology, conversations can become difficult if students do not share similar perspectives, but as educators, we balk at the idea of forcing students to all think alike. Ultimately, it is difficult to choose projects that will be appropriately challenging for students' worldviews without the perception of evangelizing one point of view. 
In line with difficulties associated with students entering community settings is the challenge of scheduling. This was of concern in all three case studies. Many of our students live and/or work off campus, which makes balancing student desires for community engagement and on-campus work difficult. Students appreciated the connection between course material and working in the community but struggled with going off campus to do the work. However, when most of the required coursework was doable without leaving campus, students reported disengagement with the parts of the local community in which the research was being done and a disconnect between the actual research and engagement with the community. Hence, finding a balance can be a nebulous adventure. Although this was a challenge, it should be noted that students largely participated equally across all three case studies (on and off campus). This may be due in part to two factors: attendance is a required part of the course and students were grouped together based on availability outside of class. Assignment to community work was based on this availability.

Lastly, it is important to prepare community members for working with students, as there were difficulties with community partners helping students navigate experiences associated with applied research. While having guest speakers come to class and having students interview community members was helpful for students, it did not necessarily allow for community members to be prepared to work on research, with which they may have little to no experience. To illustrate, one representative from the asset map project had a difficult time understanding why the information gathered in the focus groups was presented in a summative manner and scrubbed of all possible identifying characteristics, preferring the ability to identify folks who found the services provided by their organization problematic. Situations such as this, of course, place students in uncomfortable positions as they often see the community members as authoritative figures, much like they see their professors.

When community partners are members of extremely disadvantaged groups, preparation with the community partners themselves prior to the students entering the setting is especially important, but also easily overlooked. This was perhaps most evident in working with youth at the YMCA. As one might guess, it can be surprising to have a group of privileged, largely white, college students enter a space where such privilege does not exist. Indeed, it proved difficult for some of the student research teams to establish rapport. It is suggested that more loosely structured face-to-face interaction between students and community partners be incorporated prior to the collection of data via focus groups. Of course, with challenges also come successes.

\section{Successes}

One of the most immediate successes of engaging in service learning projects was the shift in students' understanding of community. As previously mentioned, this course often served as students' first real examination of social issues from a focus other than on individual factors. Even with smaller, applied projects (e.g., having them create a problem definition based on a local news story and outline a needs assessment with the individuals impacted), students seem to be taken aback by how much they learn. Indeed, it is particularly rewarding when students express sentiments such as, "THIS COURSE IS GREAT! And she had my mind working out problems I'd never thought I'd have to figure [out]," and, "[This] is the first class I've had in which I can easily explain what I've learned and relate it to every day [sic] happenings."

Students appreciated that their class projects resulted in usable products with the potential for measurable impact in the community, as opposed to simply presenting on or writing a paper about a theoretical topic or hypothetical action. For example, some of the 
students involved in the asset map contacted the first author once the project launched (i.e., a usable, interactive resource guide) and expressed gratitude for having been a part of something so important. Despite the risks of focusing on communities students may be uncomfortable working with, there are benefits of utilizing larger scale projects focused in communities with which students are familiar due to political buzz (e.g., working with the LGBTQA community during a time when marriage equality was a focus in policy changes), as is evident in the latter example.

\section{Recommendations}

Prior to integrating service learning into any course, it is first useful to consider the scope of the desired project, and whether there will be enough time to complete the project (especially if it involves off campus work) along with other course activities (papers, tests, etc.). To balance the coursework with off campus activity, the first author minimized the number of tests (two), and all writing assignments were designed to relate to the service learning project. As can be gleaned from the three case studies, it is also important to consider the types of skills - and scope of those skills-imparted through the service learning project. For example, students performed better when the skillset was limited (experience with qualitative data through focus groups and experience in survey development), as opposed to a largescale set of skills (strategic planning from start to finish and evaluation of the plan).

Preparing students for community work involves introducing key community psychology concepts, such as reflexivity, the cyclical nature of community change, and the nonlinear way problems are often solved in the applied setting, to name a few. In our experience, it became evident early on that students need these concepts to understand the structure and expectations of the projects. Indeed, previous research suggests service learning courses that do not intentionally interrupt biases before students enter the field ultimately fail (Kirkland, 2014). Structuring the course in a way where the bulk of the academic coursework (i.e., lectures, readings, etc.) occurs during the first half the term allows students to feel a greater sense of self-efficacy regarding performing up to their potential and allows students to more fully consider community contexts rather than only individual factors.

Additionally, it is important to prepare students for working with community members, especially if community members are demographically different from students. Students on the Map Evansville (asset mapping) project benefited greatly from the cultural awareness training, which prepared them for doing focus groups with community members with sexual orientations and gender identities that differed from their own. Indeed, community members expressed gratitude for students' understanding and respect during their interactions.

It is not only important to prepare students for interaction with community members, but also to prepare community members for interacting with students and interfacing with applied research. Beyond the recommended increase in face-to-face interactions mentioned earlier, this can also be done by meeting with all community members who will be involved with the project prior to introducing the students to the community setting. Doing so may lessen the abruptness of a group of students entering what are held as safe spaces for disadvantaged groups. On a similar note, it is also recommended that each partner organization be given a brief summary of what can be ethically done with the data collected, and what cannot be done.

Community psychologists would benefit from more research about community engagement in conservative areas, as conservatism can and does affect the services communities provide their members. For example, while some faith-based organizations may be able to facilitate preventative health programs for 
diseases like STIs/HIV, they may also act as a barrier to these services if they use abstinence-only programming (Brown \& Williams, 2006). Currently, there is a dearth of research on this topic. Understanding how to work within these settings, with and without student involvement, is important to moving the field forward.

Perhaps most importantly, instructors may benefit significantly from reflection about their teaching practices considering responses from students and community partners. Therefore, it may be most beneficial for instructors to solicit feedback from students at several points during the term, instead of simply waiting for end of term evaluations. This approach, as formative assessment often does, allows for modifications that ultimately benefit everyone involved. It is also recommended to have an outside evaluator conduct the formative assessment (like a focus group), as this allows students to be more open and honest. And lastly, it is of utmost importance to utilize the feedback given.

Where faculty can engage in reflection and work to connect in-class material to meaningful applied experiences, students will benefit from engaging in service learning projects while taking community psychologyrelated courses. Where service learning projects align with community needs and preparation, community members can benefit from building relationships with faculty and students engaged in applied research. While there are challenges to engaging in service learning projects in rural and conservative areas, it is possible to create experiences that benefit students and community partners in meaningful ways and allow us to create opportunities for both to empower themselves.

\section{References}

Brown, E.J. \& Williams, S.E. (2006). Southern rural African American faith communities' role in STI/HIV prevention within two counties. Journal of HIV/AIDS \& Social Services, 4, 47-62. doi: 10.1300/J187v04n03_05

Francescato, D., \& Zani, B. (2013). Community psychology practice competencies in undergraduate and graduate programs in Italy. Global Journal of Community Psychology and Practice, 4(4), 1-12. Retrieved from http://www.gjcpp.org/en/article.php?i ssue $=16 \&$ article $=79$

Howard, J. (2003). Service-learning research: Foundational issues. In S.H. Billig, \& A.S. Waterman (Eds.). Studying servicelearning: Innovations in education research methodology (pp. 1-10). New York, NY: Routledge.

Kirkland, D.E. (2014). "They look scared": Moving from service learning to learning to serve in teacher educationA social justice perspective. Equity \& Excellence in Education, 47, 580-603. doi: 10.1080/10665684.2014.958967

Map Evansville (n.d.) Map Evansville. Retrieved from http://mapevansville.com

Society for Community Research and Action (n.d.a). Competencies for community psychology practice. Society for Community Research and Action. Retrieved from http://www.scra27.org/what-wedo/practice/18-competenciescommunity-psychology-practice/

Society for Community Research and Action (n.d.b). Who we are. Society for Community Research and Action. Retrieved from http://www.scra27.org/who-we-are/

U.S. Census Bureau (2016). Quick Facts. U.S. Census Bureau. Retrieved from https://www.census.gov/quickfacts/fac 
t/table/vanderburghcountyindiana/PS

$\underline{\mathrm{T} 045217}$

U.S. Religion Census (2010). Religious

Congregations \& Membership Study.

U.S. Religion Census. Retrieved from

http://usreligioncensus.org/index.php

U.S.I. Fact Book (2017). University facts. Office of Planning, Research, and Assessment. Retrieved from www.usi.edu/planningresearch-and-assessment/usi-factbook/2017-fact-book/

Westheimer, J. \& Kahne, J. (2004). What kind of citizen? The politics of educating for democracy. American Educational Research Journal, 41, 237-269. doi: 10.3102/00028312041002237

Author Disclosure Statement: None of the authors have any commercial associations or financial interests that might create a conflict of interest in connection with this manuscript. 